\title{
FORMULAÇÃO DE PROBLEMAS DE ISOMORFISMO DE MEDIDA: ENSINO DE MATEMÁTICA NO CAMPO CONCEITUAL MULTIPLICATIVO
}

\author{
Renan Oliveira Altoé \\ Rony Cláudio de Oliveira Freitas \\ Instituto Federal do Espírito Santo \\ Programa de Pós-graduação em Educação em Ciências e Matemática \\ Vitória, Espírito Santo, Brasil \\ E-mail: renanaltoe12@gmail.com,ronyfreitas@ifes.edu.br
}

\section{Resumo:}

O objetivo deste trabalho foi o de analisar uma atividade pedagógica de formulação de problemas de matemática, elaborada com a finalidade de ensinar conceitos do Campo Conceitual Multiplicativo. Tal proposta foi construída e validada no decorrer de uma pesquisa do mestrado do Programa de Pós-graduação em Educação em Ciências e Matemática do Instituto Federal do Espírito Santo. O planejamento, a aplicação da atividade e análises de dados seguiu o pressuposto metodológico da engenharia didática. Os dados foram produzidos em uma turma de 50 ano do ensino fundamental de uma escola estadual da cidade de Vargem Alta, no Estado do Espírito Santo, Brasil, onde a atividade pedagógica também foi validada. As conclusões indicaram que a proposta teve potencial educativo pois contribuiu para o desenvolvimento da prática de formulação de problemas de matemática durante as aulas do ensino fundamental, no ensino de multiplicação e divisão. Além disso, os resultados apontaram que os problemas elaborados pelos estudantes podem contribuir na melhoria do processo de ensino e aprendizagem dos conceitos matemáticos relacionados à prática pedagógica.

\section{Palavras-Chave:}

formulação de problemas de matemática, campo multiplicativo, isomorfismo de medida, engenharia didática.

\section{FORMULATION OF PROBLEMS OF MEASUREMENT ISOMORPHISM: A TEACHING EXPERIENCE IN THE MULTIPLICATIVE CONCEPTUAL FIELD}

\begin{abstract}
This paper presents the analysis of an activity involving Problem Formulation, created to teach concepts of the Multiplicative Conceptual Field. This proposal was built and validated in a research developed in Master's Degree in Science and Mathematics Education of the Federal Institute of Espírito Santo - Ifes. The elaboration and application of the activity and analysis of the research data uses Didactic Engineering Methodology. The data were produced in a class of elementary School of the Municipality of Vargem Alta - ES, where also the activity was validated. The conclusions pointed out that the proposal has educational potential because it contributes to the practice of Problem Formulation in mathematics classes and to teaching multiplication and division. Moreover, the
\end{abstract}


results point out that the problems developed by students can contribute to the teaching and learning process of the concepts involved.

\section{Keywords:}

problem formulation, multiplicative conceptual field, isomorphism of measurement, didactic engineering.

\section{Introdução}

Desde 1945, com a publicação da obra "How To Solve It" de George Pólya, estudos relativos à Resolução de Problemas viveram momentos de turbulência, uma vez que diferentes concepções e conceituações a seu respeito eclodiram em pesquisas científicas. Nesse período, houve mudanças significativas que a elevaram ao patamar de metodologia de ensino em matemática. Por volta da década de 1980, - National Council of Teachers of Mathematics (NCTM) apontou algumas recomendações para o ensino de matemática e destacou a Resolução de Problemas como um caminho promissor. No entanto, somente na década seguinte, é que se constituiu um conjunto de estratégias para o ensino e o desenvolvimento da aprendizagem de matemática (DINIZ, 2001).

No interior dessa metodologia, resolver problemas tem sido considerado o ponto chave. Nesse sentido, o professor é o responsável em propor os problemas de matemática, enquanto que os discentes, por resolvê-los. Essa visão, ainda presente nas práticas pedagógica de muitos professores, necessita de novas reflexões tendo em vista que os educandos podem também assumir o papel de propositores de problemas, ação relativa a uma prática chamada de "Formulação de Problemas" ou "Problem-posing" e que vem sendo alvo de estudos há algum tempo (BROWN e WALTER, 1983; KILPATRICK, 1987; SILVER e MAMONA, 1989; SILVER, 1994, 1997; SILVER et al., 1996; ENGLISH, 1997, 1998; SILVER e CAI, 1993, 1996, 2005). Para Boavida et al. (2008), Dante (2009) e Chica (2001), a relevância dessa prática nas aulas de matemática está na possibilidade de se desenvolver a capacidade crítica do aluno, seu pensamento e contribuir na expressão de ideias, relações e no aprofundamento de conceitos. Dessas concepções, desponta-se o respeito aos saberes dos educandos, firmemente defendido por Freire (2015), como papel central na aprendizagem.

O objetivo deste trabalho foi o de analisar uma atividade pedagógica de formulação de problemas de matemática, elaborada com a finalidade de ensinar conceitos do Campo Conceitual Multiplicativo, com vista ao ensino dos conteúdos de matemática de multiplicação e divisão na Teoria dos Campos Conceituais, intitulada "A compra misteriosa". Tal proposta foi construída e validada no decorrer de uma pesquisa do mestrado do Programa de Pós-graduação em Educação em Ciências e Matemática do Instituto Federal do Espírito Santo. O planejamento, a aplicação da 
atividade e análises de dados seguiu o pressuposto metodológico da engenharia didática. Os dados foram produzidos em uma turma de 50 ano do ensino fundamental de uma escola estadual da cidade de Vargem Alta, no Estado do Espírito Santo, Brasil, onde a atividade pedagógica também foi validada.

Em busca de orientar a leitura e o entendimento deste trabalho, há necessidade de discutir, brevemente, a respeito dos seguintes tópicos: i) Formulação de Problemas; ii) Campo Conceitual Multiplicativo e iii) Engenharia Didática. Nosso intuito não é o de cristalizar os estudos relativos à Formulação de Problemas por meio da atividade que será apresentada, mas alavancar novos olhares relativos à sua proposição em sala de aula e, quando possível, fomentar novos interesses por outros profissionais da área.

\section{Desenvolvimento}

\subsection{Formulação de Problemas}

Iniciamos esta seção nos apropriando do pensamento de Pozo (1998) quando diz que uma mesma situação pode representar um problema ${ }^{1}$ para uma pessoa e para outra não, seja porque não Ihe interessa ou porque possui mecanismos traçados para solucioná-lo. Nesse mesmo sentido, Dante (2009, p. 11) afirma que "o que é um problema para alguns pode não ser para outros, ou o que é um problema num determinado contexto pode não ser em outro". A partir desses apontamentos, cremos ser necessário discutir sobre a Formulação de Problemas nas aulas de matemática, incluindo o protagonismo discente.

Ressaltamos o lugar da Formulação de Problemas e a consideramos uma prática dentro da metodologia de Resolução de Problemas. Fundamentamos tal perspectiva nos estudos de Silver (1994), quando aponta que é uma prática que ocorre dentro do processo de resolução de problemas e, no posicionamento de D'amore (2014, p. 29, tradução nossa) ao anunciar que "a Formulação de Problemas é um modo de colocar-se no interior da Resolução de Problemas e que as duas problemáticas não são opostas, mas muito perto".

Segundo Silver (1994), os alunos são quase sempre convidados a resolver os problemas apresentados pelo professor ou pelos livros didáticos e são, raramente, convidados a apresentarem seus próprios problemas de matemática. Formular problemas se constitui de prática curiosa e pode despertar o interesse pela sua resolução. Nesse sentido, "aos alunos deve ser dada a oportunidade para formular problemas de determinadas situações e criar novos problemas quando modificando

\footnotetext{
${ }^{1}$ Entendemos por problema qualquer situação capaz de envolver os educandos em investigação, na qual as estratégias de resolução não são visíveis em um primeiro momento e que as propor é um ato criativo, curioso, engenhoso, motivador e que desenvolve o pensamento crítico-reflexivo.
} 
as condições de um determinado problema" (NCTM, 1991, p. 95). Pressupomos que, dependendo da maneira como a Formulação é trabalhada, a mesma pode oportunizar a formulação de problemas que abarquem contextos de interesse dos alunos, incentivando a inventividade e a descoberta.

Em busca de uma conceituação para a temática, Silver (1994, p. 19, tradução nossa) anuncia que formular problemas "[...] refere-se tanto a produção de novos problemas e a reformulação de determinados problemas". Nesse processo, Boavida et al. (2008) salienta que a atividade de formular problemas é de importância inquestionável, na medida que contribui no aprofundamento de conceitos de matemática. Nessa ótica, nas aulas de matemáticas, "as crianças podem inventar os próprios problemas. Isso as motivará a ler, compreender e resolver os problemas, porque são seus" (DANTE, 2009, p. 65).

Outras contribuições dessa prática evocam-se do posicionamento de Boavida et al. (2008, p. 27) ao afirmar que "encorajar o aluno a escrever, partilhar e resolver os seus próprios problemas, é um contexto de aprendizagem muito rico para o desenvolvimento da sua capacidade de resolução de problemas". No decorrer da formulação do problema, "[...] os alunos apercebem-se da sua estrutura desenvolvendo, assim, pensamento crítico e capacidade de raciocínio ao mesmo tempo que aprendem a exprimir as suas ideias de modos mais preciso" (BOAVIDA et al., 2008, p. 27).

Durante a aprendizagem, é importante que o aluno acredite em si mesmo e na sua capacidade de aprender, de criar e de estabelecer relações. Por esse ângulo, Diniz (2001) relata que a Formulação de Problemas tem sua contribuição uma vez que no processo de gerar problemas, o aluno participa ativamente de um fazer em matemática que desenvolve, para a além da linguagem, o interesse e confiança em seu modo de pensar. Sendo assim, "quando o aluno cria seus próprios textos de problemas, ele precisa organizar tudo o que sabe [...], dando-lhe sentido a estrutura adequada para que possa comunicar o que pretende" (CHICA, 2001, p. 151). É uma prática que retira do educando seu papel de resolver de problemas, para um "propositor de problemas, vivenciado o controle sobre o texto e as ideias matemáticas" (CHICA, 2001, p. 151). Logo,

[...] é preciso estimular a capacidade inventiva e questionadora dos alunos, desenvolvendo na sala de aula um clima de interação e respeito, onde se possa fazer matemática através da possibilidade de questionar, levantar hipóteses, comunicar ideias, estabelecer relações e aplicar conceitos (CHICA, 2001, p. 153). 
Diante do exposto, formular problemas não só contribui no desenvolvimento de capacidades investigativas, mas pode gerar laços de confiança e respeito entre os alunos e o professor. Leva-se em conta o entusiasmo necessário para se aprender matemática e o direito de participar e vivenciar novas aprendizagens.

A proposição da Formulação de Problemas em sala de aula pode ocorrer por meio de diferentes caminhos. Nos estudos de Chica (2001), temos que um problema pode ser elaborado a partir das seguintes ideias: i) criar um problema a partir de um problema dado; ii) criar um problema a partir de uma figura; iii) criar um problema a partir de um problema iniciado; iv) criar um problema parecido a partir de um problema dado; v) criar um problema a partir de uma pergunta; vi) criar um problema a partir de uma palavra; vii) criar um problema a partir de uma resposta dada; viii) criar um problema a partir de uma operação matemática; ix) criar um problema a partir de um tema e $\mathrm{x}$ ) criar um problema com um determinado tipo de texto.

Assim, definimos que a Formulação de Problemas é uma prática inserida na metodologia de Resolução de Problemas que oportuniza os alunos a (re) formularem problemas a partir de determinadas condições pré-determinadas ou problemas dados. Tal prática envolve autenticidade, criatividade, motivação intrínsecas ou extrínsecas, significados, contextos (reais ou imaginários) e conceitos matemáticos. Nesse processo, espera-se desenvolver no aluno o pensamento crítico-reflexivo, o raciocínio, a capacidade de comunicar ideias, de estabelecer relações e significados, de observação e argumentação e de reflexão sobre suas ações e seus processos de pensamento. Por fim, formular e resolver estão estreitamente interligadas uma vez que um dos sentidos de se formular um problema é buscar a sua resolução.

Apresentamos, abaixo, alguns conceitos inerentes à definição apresentada, visto que poderiam levar a diferentes interpretações.

- Criatividade: a capacidade de produzir problemas entre a relação condiçãocontexto ou na reformulação de um problema dado, cujo produto final seja original ou incomum;

- Significados: diz respeito ao estabelecimento de relações entre conceitos matemáticos e contexto do problema. Caso um educando seja convidado a formular um problema que envolva a operação matemática $3 \times 2$ e ao apresentá-lo retrata "possuir 3 camisas e 2 calças, quantas maneiras poderia uma pessoa se vestir", mostrará uma compreensão de multiplicação como combinatória;

- Autenticidade: trata-se de interesses intrínsecos. Temos assim, um conceito de autenticidade direcionado a construção de problemas únicos os quais 
diferem-se dos demais e que apresentam aspectos relacionais unicamente pessoais;

- Motivação Intrínseca ou Extrínseca: Quanto a motivação intrínseca, trata-se de sentimentos e emoções singulares de cada indivíduo, como por exemplo, gostar de matemática. Já a motivação extrínseca diz respeito a uma ação externa que contribui para que o aluno se motive intrinsecamente no processo de formulação, como por exemplo, o professor explicar que formular problemas é interessante e divertido;

- Contextos (reais ou imaginários): nos referimos a situações cotidianas vividas (contexto real) ou não (contexto imaginário) pelos educandos.

Portanto, acreditamos que a Formulação de Problemas pode contribuir no ensino de matemática e, por isso, deve estar mais presente nas aulas de matemática e não deve constituir-se somente de prática curiosa, mas considerá-la potencializadora de aprendizagens matemáticas.

\subsection{Campo Conceitual Multiplicativo: Multiplicação e Divisão}

O Campo Conceitual Multiplicativo abarca as relações quaternárias (isomorfismo de medida) e as relações ternárias (produto de medidas e comparação multiplicativa). Neste artigo, focaremos nossos olhares somente para a relação quaternária que é o foco da atividade que será apresentada em seções posteriores.

Segundo Vergnaud (2014), uma relação quaternária acontece entre quatro quantidades: duas quantidades são medidas de um tipo e outras duas, de outro. São exemplos desta relação: i) Vitória é para o Espirito Santo o que Curitiba é para o Paraná; ii) o preço de 5 bombons está para o preço de um bombom assim como 5 bombons estão para um bombom, dentre outros exemplos. Nesse tipo de conceituação estão as relações de proporcionalidade (simples, dupla ou múltiplas) que podem ser representadas por uma tábua que contém quantidades que se correspondem e cujos valores podemos determinar mediante uma multiplicação ou uma divisão. Nesta seção, discutiremos somente a proporcionalidade simples, alvo de discussão da atividade aplicada na pesquisa.

No âmbito do isomorfismo de medidas, a multiplicação é estruturada em uma classe que respeita a relação descrita abaixo e segue o caráter discreto ou contínuo

\footnotetext{
${ }^{2}$ O Campo Conceitual Multiplicativo ou das Estruturas Multiplicativas refere-se a todas as situações que podem ser analisadas como problemas de proporções simples e múltiplas para os quais geralmente é necessária uma multiplicação, uma divisão ou uma combinação dessas operações para resolvê-los (MOREIRA, 2015). “O conceito de situação empregado por Vergnaud não é o de situação didática, mas sim o de tarefa, sendo que toda situação complexa pode ser analisada como uma combinação de tarefas [...]" (MOREIRA, 2015, p. 211, grifo nosso)
} 
das quantidades em jogo ou segundo a propriedade dos números utilizados (VERGNAUD, 2014).

\section{Multiplicação}

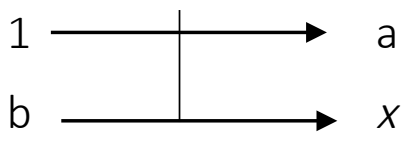

Vergnaud (2014, p. 239) apresenta o seguinte exemplo para ilustrar esse pensamento: "Tenho 3 pacotes de iogurte. Há 4 iogurtes em cada pacote. Quantos iogurtes eu tenho?".

A representação dessa situação, seguindo o esquema acima, é assim apresentada:

Dimensão

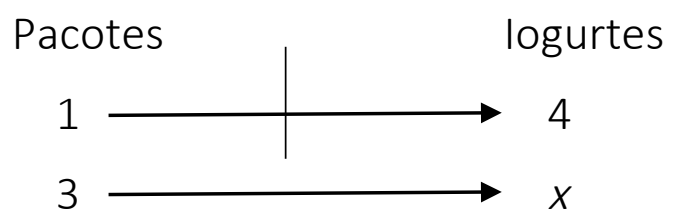

De acordo com Vergnaud (2014), a esquematização acima é nada mais que um quadro de correspondência entre duas espécies de quantidades. A resposta para esse problema é 12 iogurtes e pode ser resolvido a partir da utilização de operadores intitulados de "operador-escalar" e "operador-função". Inserindo tais operadores no exemplo acima, temos:

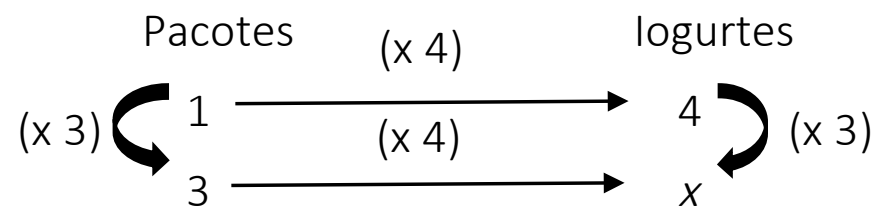

Seguindo a lógica de Vergnaud (2014), em relação ao comportamento dos operados, os números 1 e 3 representam quantidades de pacotes, portanto, são medidas. Já os números 4 e $x$ também são considerados medidas, mas de outra natureza. A resolução desse problema poderia acontecer aplicando, seja o operadorescalar (sem dimensão) ou o operador-função. Para melhor distinção, o vertical (escalar) permitiria passar de uma linha à outra mesma categoria de medida, enquanto que o horizontal (função) expressa a passagem de uma categoria à outra, de onde emerge o emprego de uma forma que expressa a relação: iogurte por 
pacote = iogurte/pacote. Dessa forma, em relação ao operador-escalar, da mesma forma que se passa de 1 pacote para 3 pacotes, passa-se de 4 iogurtes para $x$ iogurtes, enquanto que o operador-função faz passar de 1 pacote a 4 iogurtes que é o mesmo que passar de 3 pacotes a $x$ iogurtes.

No tocante da divisão, no âmbito do isomorfismo de medidas, Vergnaud (2014) traz a ideia dessa operação em duas classes distintas: "divisão: busca de valor unitário" ou "divisão: busca de quantidade de unidades". Essas especificações estão, respectivamente, relacionadas à "divisão como partilha equitativa (partição) " e a "divisão como medida (cotição)."

Relativo à "divisão como partilha equitativa (partição) ", Vergnaud (2014) apresenta a seguinte esquematização:

\section{Divisão: busca de valor unitário}

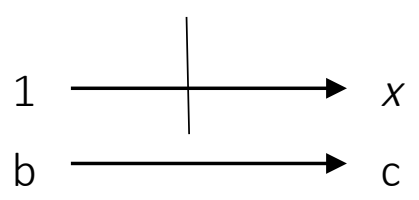

Dessa relação, temos a divisão de uma quantidade em partes iguais e, nesse sentido, uma correspondência de um-para-um. Em suma, são situações para as quais objetiva-se determinar o valor unitário, ou seja, o valor que "cabe" a cada um dos elementos do divisor. Vergnaud (2014) apresenta a seguinte situação que the corresponde: "Paguei R\$12,00 por 3 garrafas de vinho. Quanto custa cada garrafa?".

Organizando os dados em uma relação dimensional, temos:

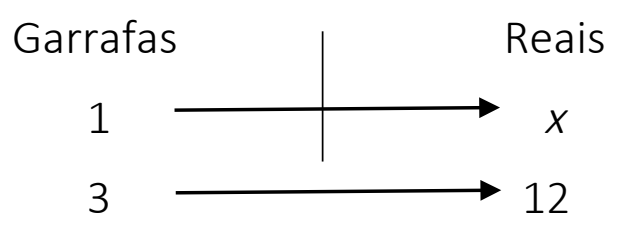

De acordo com Vergnaud (2014), esse tipo de problema pode ser resolvido por meio de uma divisão. É preciso encontrar o valor unitário partindo do conhecimento de correspondência entre "garrafas e reais". Assim, a solução pode ser determinada seguindo dois caminhos: i) inversão do operador escalar ou ii) o fator em falta, ou seja, por tentativa e erro. No caso (i), o discente pode lançar mão do seguinte "Teorema-em-ação": dividir 12 reais pelas 3 garrafas. Já para o caso (ii), poderia ser utilizado o "Teorema-em-ação": que número multiplicado por 3 dá 12 reais?

\footnotetext{
${ }^{3}$ Segundo Vergnaud (1996), o Teorema-em-ação é uma proposição tida como verdadeira ou falsa em uma determinada situação. Se constitui de relações matemáticas elaboradas pelos alunos ao escolherem uma operação ou uma Revista Eletrônica DECT, Vitória - Espírito Santo, V. 7, N. 01, p. 103-128, Abril de 2017 
Na esfera da "divisão como medida (cotição) ", Vergnaud (2014) traz a seguinte relação:

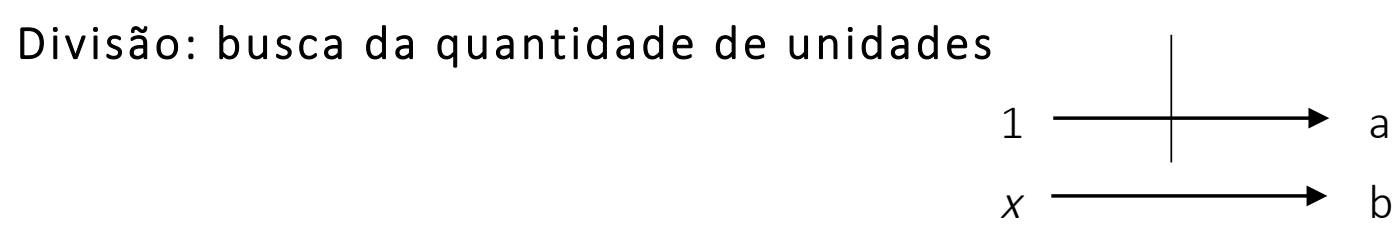

A divisão como medida é utilizada quando o dividendo e o divisor possuem a mesma natureza, ou seja, interessasse determinar o número de grupos partindo do conhecimento da dimensão de cada grupo. Os problemas desse tipo estabelecem uma relação da "parte" para se chegar ao "todo" e o seguinte exemplo, apresentado por Vergnaud (2014), discute essa relação: "Pedro tem R\$12,00 e quer comprar pacotes de balas a R\$ 4,00 o pacote. Quantos pacotes ele pode comprar?".

Vejamos sua esquematização:

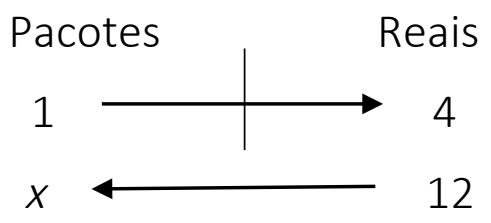

Para esse exemplo, Vergnaud (2014, p. 242) diz que "divide-se R\$12,00 por 4 para se obter $x$ pacotes tal como o representa a relação horizontal da direita para a esquerda". Para ele, a operação (:4) relaciona-se a uma função inversa da função direta (xR\$4,00/pacotes), que permite passar para a linha de cima, de um pacote ao preço de um pacote. Nesse sentido, tal problema poderia ser resolvido seguindo dois procedimentos, tais como: i) inversão do operador funcional ou ii) aplicação do operador escalar. Para o primeiro, encontra-se o seguinte "Teorema-em-ação": dividir os R\$ 12,00 em grupos de R\$ 4,00, enquanto que o “Teorema-em-ação" do item (ii) é: quantas vezes $\mathrm{R} \$$ 4,00 cabe em $\mathrm{R} \$ 12,00$.

Sendo assim, esses são os olhares relativos a multiplicação e a divisão que se buscamos encontrar nos problemas formulados pelos alunos.

sequência de operações para resolverem uma determinada situação, tendo por base um Conceito-em-ação (é um objeto, um predicado ou uma categoria de pensamento tida como pertinente não podendo ser falsa ou verdadeira). Tomemos o exemplo: Resolva a operação 32×12. Nesse caso, um Conceito-em-ação poderia ser "adição de repetidas parcelas iguais" e um Teorema-em-ação seria "adicionar finitamente quantidades iguais, tem por base um número que diz quantas vezes deve ser escrito essas quantidades." 


\subsection{Engenharia Didática}

Considerando seu lado estritamente metodológico, a Engenharia Didática é uma metodologia que vincula a dimensão teórica ao campo experimental da prática educativa, tão importantes nas pesquisas em Educação Matemática. Nesse sentido, é "[...] uma analogia entre o trabalho do pesquisador em didática e o trabalho do engenheiro, no que diz respeito a concepção, planejamento e execução de um projeto" (PAIS, 2011, p. 99).

Almouloud e Coutinho (2008) e Almouloud e Silva (2012) denotam que a Engenharia Didática, entendida como metodologia de pesquisa, caracteriza-se, em primeiro lugar, por um esquema experimental baseado em "realizações didáticas" em sala de aula, isto é, na concepção, realização, observação e análise de sessões de ensino, permitindo a validação interna a partir do confronto entre as análises à priori e à posteriori.

A Engenharia Didática segue algumas fases que são importantes para o bom êxito da pesquisa. Para Pais (2011), são elas: 1) análises preliminares; 2) concepção e análise à priori; 3) aplicação de uma sequência didática e 4) análise à posteriori e a avaliação. Na pesquisa desenvolvida, foi adotada a nomenclatura da terceira fase como "Aplicação de uma sequência de atividades", devido a ausência de uma sequência didática propriamente dita.

A primeira fase, intitulada "análises preliminares", tem como objetivo a "[...] elaboração de um quadro teórico sobre o qual o pesquisador fundamenta suas principais categorias" (PAIS, 2011, p. 101). Neste artigo, ela está representada, brevemente, pelas seções 2.1 e 2.2, além dos estudos relativos a revisão de literatura, análise do livro didático utilizado pela professora regente e observações em sala de aula, os quais não aparecem no decorre deste trabalho por não atenderem ao objetivo proposto.

A segunda fase, descrita por "concepção e análise à prior", consiste na definição, a partir das análises preliminares, das variáveis que serão consideradas na construção da proposta didática. São as variáveis macrodidáticas ou globais, estas relativas à organização da engenharia como um todo e as variáveis microdidáticas ou locais, relacionadas à organização local da engenharia, ou seja, ao planejamento específico de uma sessão da sequência didática (PAIS, 2011). Esta segunda fase será apresentada na seção seguinte intitulada "A atividade de formulação de problemas e sua análise à priori."

A "aplicação de uma sequência de atividades", considerada a terceira fase, consiste na aplicação das atividades elaboradas na fase precedente. Para Almouloud e Silva (2012), é o momento de estabelecer o contrato didático e registrar as 
observações feitas durante a experimentação. Esta fase será apresentada por intermédio da seção "Relatos substanciais da atividade."

Por fim, a quarta fase, nominada "análise à posteriori e a avaliação", refere-se ao tratamento das informações obtidas na aplicação da atividade. É importante atingir a realidade da produção dos alunos, desvelando seus procedimentos de raciocínio. Almouloud e Coutinho (2008) afirmam que a análise à posteriori de uma determinada sessão é o conjunto de resultados extraídos da exploração dos dados recolhidos, enquanto que a avaliação, é para Pais (2011, p. 103), "obtida pela confrontação entre os dados obtidos na análise à priori e à posteriori, verificando as hipóteses feitas no início da pesquisa". Neste artigo, será representada pela seção "Análise à posteriori da atividade."

\section{A Atividade de Formulação de Problemas}

\subsection{Variáveis macrodidáticas e microdidáticas}

Após as análises relativas à primeira fase, adotamos as variáveis discriminadas abaixo na construção da atividade. Neste artigo, destacamos, com relação às microdidáticas, somente aquelas relativas à atividade que será apresentada.

\section{Macrodidáticas:}

I. (Re) construção sobre a metodologia de ensino;

II. Valorização à descoberta;

III. Incentivo à criatividade;

IV. Valorização da percepção de conexões entre as operações de multiplicação e divisão e problemas que envolvem o cotidiano.

\section{Microdidáticas:}

I. Multiplicação: proporcionalidade;

II. Divisão: divisão como partilha equitativa (partição).

\subsection{A atividade e sua análise à priori}

Oriunda da parceria entre pesquisador e professora regente da turma, foi elaborada a atividade "A compra misteriosa" que é protagonizada por um menino e sua mãe que vivem em uma cidade chamada "Cidade das Festas". No decorrer da história, é encontrado um bilhete, sujo e molhado no qual não foi possível ver algumas informações. Entretanto, o menino e sua mãe, descobrem que se trata de um comprovante de compras que caiu de uma das sacolas de sua mãe. 
Figura 1: Atividade 1. Fonte: Dados da pesquisa.

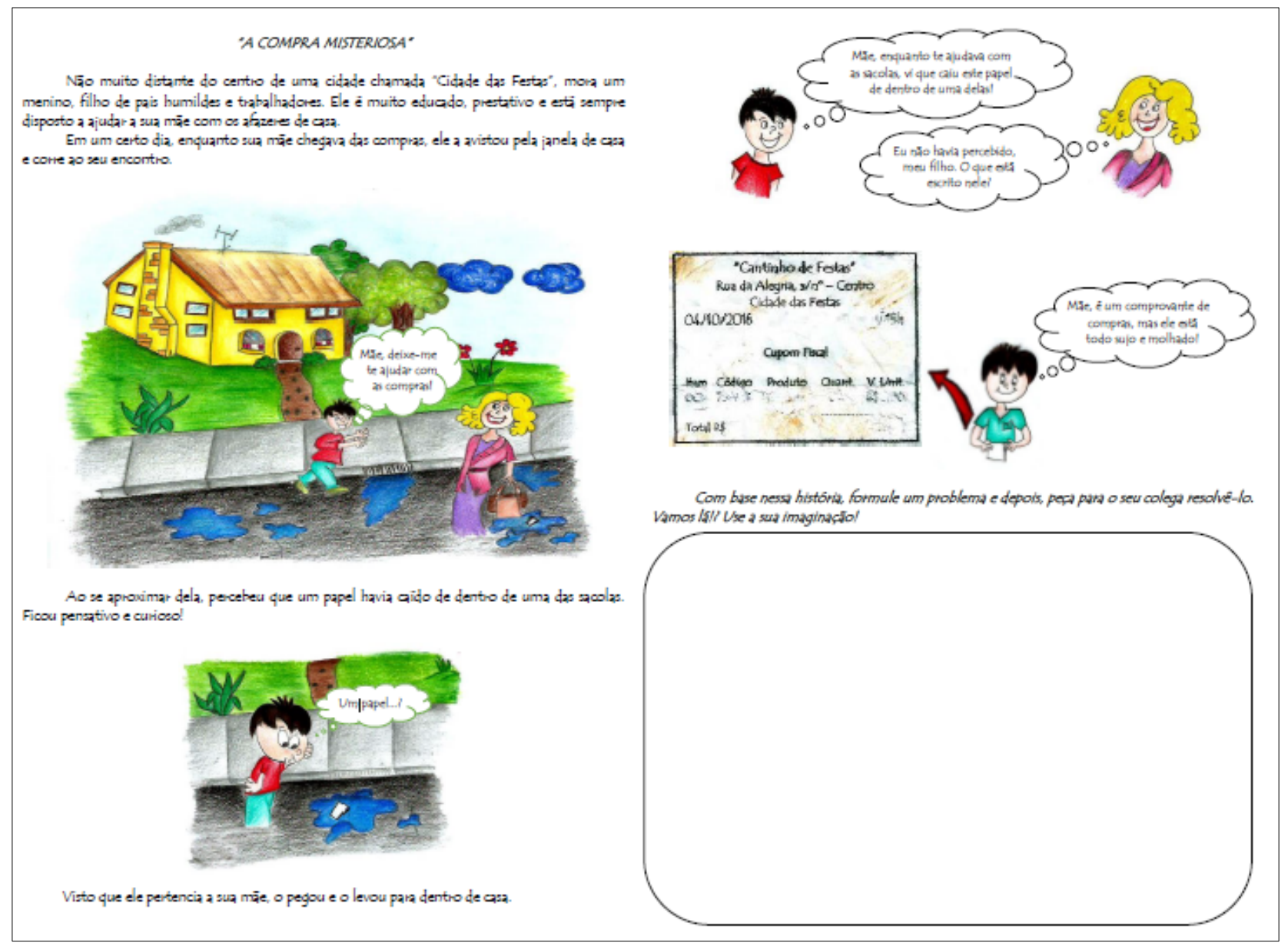

A análise à priori para esta atividade foi desmembrada em três categorias distintas, a saber:

\section{Quadro 1: Análise à priori da Atividade 1. Fonte: Dados da pesquisa.}

\begin{tabular}{|l|l|}
\hline Dimensão Didática & Que a proposta contribua na formulação de problemas. \\
\hline \multirow{5}{*}{ Dimensão Epistemológica } & $\begin{array}{l}\text { Que os problemas formulados sejam de proporção simples, envolvendo } \\
\text { multiplicação ou divisão como partilha equitativa (partição). }\end{array}$ \\
\cline { 2 - 3 } Outras Especificações & $\begin{array}{l}\text { Que alguns ou todos os problemas desta Dimensão possibilitem discussões } \\
\text { acerca do enunciado, da resolução ou da solução. }\end{array}$ \\
\hline & $\begin{array}{l}\text { Que seja atribuído nome aos personagens e possibilidade (s) para o (s) } \\
\text { produto (s) comprado (s). }\end{array}$ \\
\cline { 2 - 3 } & $\begin{array}{l}\text { Que os alunos expressem, nos problemas formulados, seus interesses } \\
\text { pessoais. }\end{array}$ \\
\hline
\end{tabular}

Na tentativa de obter melhores resultados na aplicação da atividade, foram elaboradas algumas "Orientações ao Professor (a) ", tais como: 
- Antes de apresentar a história "A compra misteriosa", dialogue com seus alunos e questione se eles já foram às compras com sua mãe, seja em um supermercado ou em outro estabelecimento;

- Após a elaboração dos problemas e suas respectivas resoluções, distribua os problemas elaborados de forma aleatória entre os alunos. É o outro colega da sala que deverá resolver o problema do outro;

- Solicite aos discentes, no término da aula, que registrem em uma folha os motivos que o levaram a elaborar o seu problema. Eles podem pensar nos seguintes aspectos: os nomes dos personagens, a pergunta do problema, os produtos comprados, a operação envolvida, o sentido do problema para ele etc.;

- Ajude os alunos que apresentarem dificuldades. Todos devem, apesar delas, formular o seu problema;

- A expressão "pais humildes" e as palavras "prestativo" e "afazeres" podem ser desconhecidas e necessitem de melhores explicações. Caso necessário, explique-as!

\section{Relato da atividade}

Esta atividade foi realizada com 28 alunos, os quais se demonstraram curiosos em saber como seria e o que deveriam fazer. Conforme sugerido, iniciamos as discussões a partir das "Orientações ao Professor (a)" indicadas para a atividade (ver Análise à priori da Atividade 1).

Quando questionados sobre a ocasião de já terem acompanhado suas mães às compras, seja em um supermercado ou em outros estabelecimentos, todos os alunos afirmaram que sim. Abaixo, podemos ver duas dessas afirmações.

Sim. Eu já fui no supermercado com minha mãe fazer compras para casa (novembro/2016).

[...] na loja de roupas da amiga da minha mãe (novembro/2016).

No decorrer das discussões, os alunos mencionavam gostar muito de comprar balas, chocolates e produtos alimentícios, como, por exemplo, biscoito, bolo, pão, entre outros. Após, cada aluno recebeu uma cópia da atividade "A compra misteriosa" e aos poucos brotaram as primeiras dificuldades. A princípio, instaurouse como obstáculo o comando da atividade, ou seja, "Com base nessa história, formule um problema...". Os alunos não tinham ideia do que era para ser feito e, muito menos, o que seria formular um problema. Diante disso, foi possível perceber que aquele grupo de alunos não tinha ainda vivenciado a prática de Formulação de 
Problemas e era, portanto, a primeira vez. Assim, pôde-se concluir que era algo novo e desafiador.

Para que a aula pudesse transcorrer, foi necessário discutir com os estudantes o que é formular um problema e, para melhor entendimento, demos um exemplo cuja pergunta referia-se ao valor unitário de uma camisa, uma vez que duas custam $\mathrm{R} \$ 38,50$. A partir de então, alguns alunos começaram a proferir que tinham que formular aqueles "negocinhos" que a professora levava para sala de aula e pedia para eles resolverem.

Conforme sugestão das "Orientações ao Professor (a) ", realizamos a troca dos problemas entre os estudantes. Nesse momento, é importante pontuar o entusiasmo dos alunos em estar diante do problema elaborado pelo outro colega. Ademais, todas as vezes que o problema parecia confuso ou faltava alguma informação que impedia de resolvê-lo, o resolvedor se colocava diante do formulador para discutirem possíveis erros no problema. Entendemos que esse envolvimento conduz ao desenvolvimento da capacidade de pensar criticamente e de refletir a respeito das operações envolvidas no problema, suas relações e conceitos.

5. Análise à posteriori da atividade

Para melhor orientar esta seção, optamos por apresentar às análises à posteriori trazendo o Quadro 1, relativo à análise à priori.

\section{Dimensão Didática}

Que a proposta contribua na formulação de problemas.

Nesta Dimensão, esperávamos que a atividade contribuísse na formulação de problemas. Sendo assim, nosso intuito é verificar se os alunos conseguiram elaborar os seus problemas a partir da atividade "A compra misteriosa". Após analisarmos os registros escritos dos participantes, identificamos 28 problemas formulados, os quais serão melhor analisados na próxima Dimensão.

Percebemos que todos os problemas formulados pelos participantes retratavam o contexto de uma compra e isso tem forte ligação com o comando da atividade, quando Ihes é solicitado formular um problema com base na história. $O$ comprovante, apresentado no final da história, se constituiu de um importante elemento no processo de elaboração do problema, uma vez que apresentou as expressões "Quantidade", "Valor Unitário" e "Total" e que, quando relacionadas, podem caracterizar as operações de multiplicação e divisão. Assim, os participantes 
poderiam associar as duas primeiras para expressar uma multiplicação ou a última com a primeira, para exprimir uma divisão como partilha equitativa (partição).

Dessa forma e diante do êxito na resposta ao comando da atividade, concluímos que a história "A compra misteriosa" contribuiu na prática de formulação de problemas à medida que apresentou um possível caminho para se pensar a elaboração do problema. Essa proposta de atividade se aproxima um pouco com um caminho apresentado por Chica (2001), quando destaca a possibilidade de se trabalhar a formulação "a partir de um início dado, continuar o problema". Segundo a autora, nesse tipo de proposta, "[...] nem todos os dados estão disponíveis na parte inicial [...]; portanto, é preciso colocar outros, relacionar os dados oferecidos com os criados, articular o texto de acordo com a situação iniciada" (CHICA, 2001 p. 156).

\begin{tabular}{|l|l|}
\hline \multirow{2}{*}{ Dimensão Epistemológica } & $\begin{array}{l}\text { Que os problemas formulados } \\
\text { sejam de proporção simples, } \\
\text { envolvendo multiplicação ou } \\
\text { divisão como partilha equitativa } \\
\text { (partição). }\end{array}$ \\
\cline { 2 - 2 } & $\begin{array}{l}\text { Que alguns ou todos os problemas } \\
\text { desta Dimensão possibilitem } \\
\text { discussões acerca do enunciado, da } \\
\text { resolução ou da solução }\end{array}$ \\
\hline
\end{tabular}

As análises relativas a essa Dimensão tratam das operações matemáticas envolvidas nos problemas formulados. A princípio, esperávamos que fossem situações de proporção simples, cuja multiplicação ou divisão como partilha equitativa (partição) estivessem presente. Segundo Vergnaud (2014), a partição é considerada a "busca por valor unitário" e se enquadra em um isomorfismo de medida, o qual coloca em jogo quatro quantidades.

Assim, identificamos, do total de 28 formulações, 25 propostas que se enquadraram nas expectativas desta Dimensão. Delas, 21 expressam a multiplicação, 3 envolvem multiplicação e divisão como partilha equitativa (partição) e 1 somente a divisão como partilha equitativa (partição). Os demais 3 problemas retrataram a adição e a subtração. A identificação dos problemas que expressam, seja uma multiplicação, uma divisão, ou ambas as operações, será apresentada a seguir tomando por base características nos enunciados dos problemas e nas discussões relativas às operações. Para que os alunos consigam formular ainda melhor suas produções, Chica (2001) aponta para a necessidade de um planejamento inicial relacionado a escrita do problema, o que se deseja retratar na elaboração, relendo e 
revendo o que foi escrito. O que a autora sustenta é a melhoria da prática por meio da reflexão e releitura constante da proposta inicialmente apresentada pelo aluno. Nesta pesquisa, temos considerado a existência de boas produções, sobretudo capazes de promoverem aprendizagens a respeito das operações matemática em destaque.

No tocante dos problemas de multiplicação, os alunos registraram a relação de "uma determinada quantidade" com o "valor de cada uma dessa quantidade" para representá-la. Isso se confirma, por exemplo, nos problemas de A28-11 e de A10-11 exibidos nas Figuras 2 e 3.

Figura 2: Problema do aluno A28-11. Fonte: Arquivo dos autores.

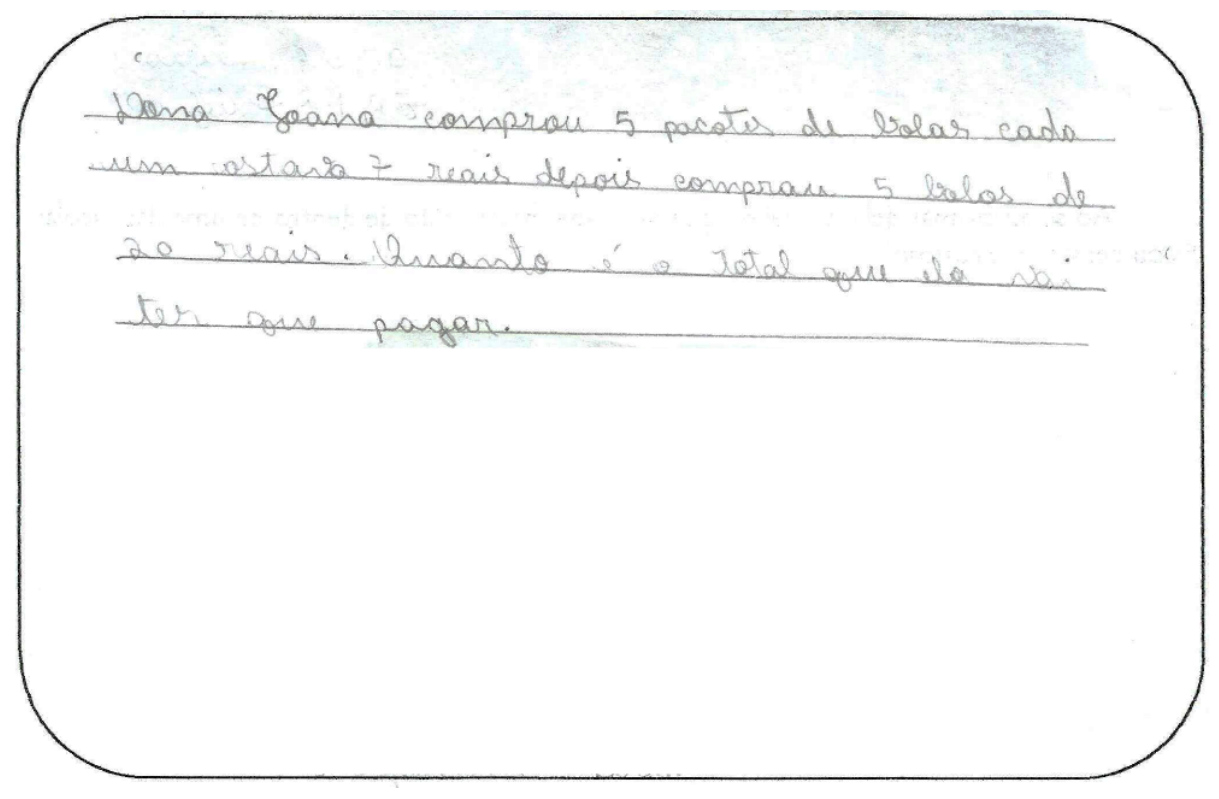

Figura 3: Problema do aluno A10-11. Fonte: Arquivo dos autores.

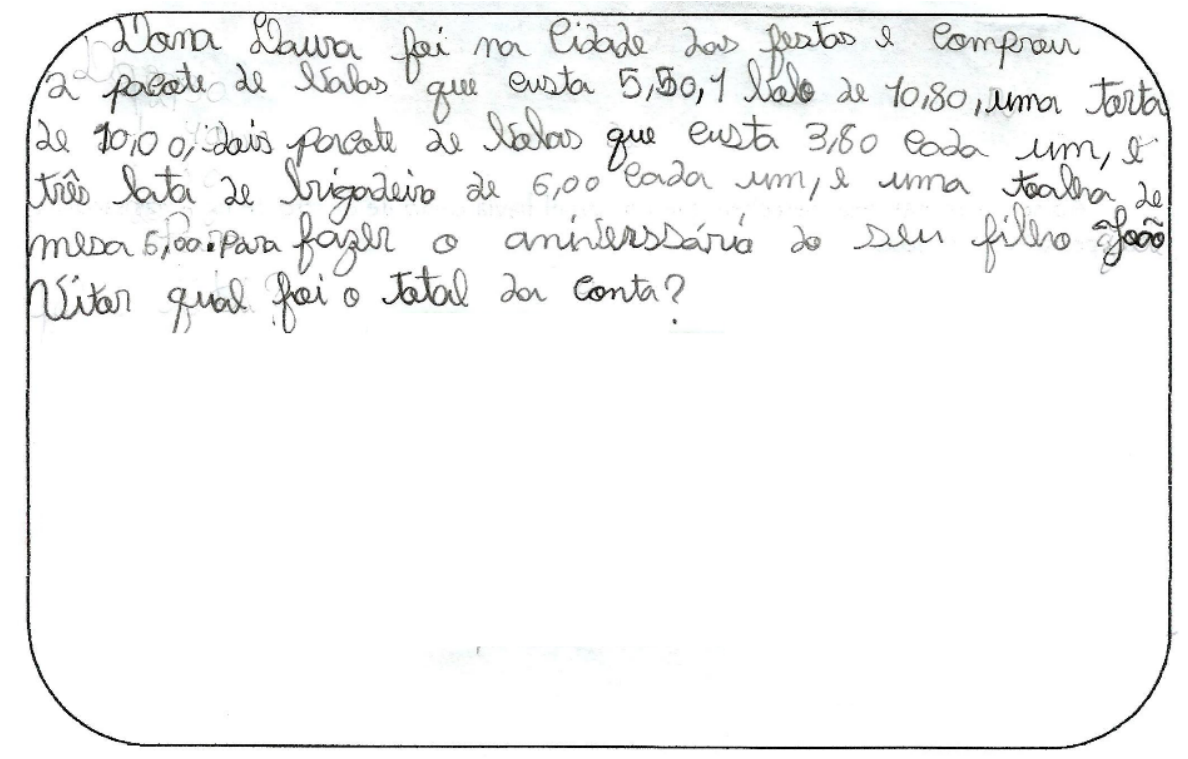


A resolução desses problemas poderia ser realizada a partir da multiplicação das "quantidades de cada produto" com seu respectivo "valor unitário" e, após, somar os resultados encontrados. Além disso, são caracterizados problemas de proporção simples uma vez que envolvem a relação entre duas grandezas (quantidade e valor unitário), mesmo que nas produções dos alunos seja necessário efetuar várias multiplicações.

Tomando o exemplo da Figura 3, a afirmativa "dois pacotes de bolas que custa 3,80 cada", remete uma relação de proporcionalidade que pode ser assim representada:

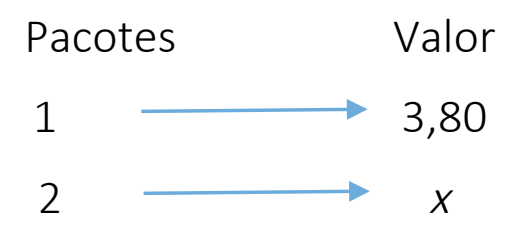

A resolução dessa proporção pode ocorrer, conforme aponta Vergnaud (2014), a partir de um "operador-escalar" ou "operador-função". O operador-escalar permite passar de uma linha à outra na mesma categoria de medida, ou seja, dobrando-se a quantidade de pacotes, dobra-se o valor. Já o operador-função expressa a passagem de uma categoria à outra, que nesse caso expressa uma relação: Valor por pacotes = valor/pacotes. Assim, da mesma maneira que se passa de 1 pacote para $R \$ 3,80$, passa-se de 2 pacotes para $x$ valor. Vejamos como esses operadores se encaixam na relação proporcional.

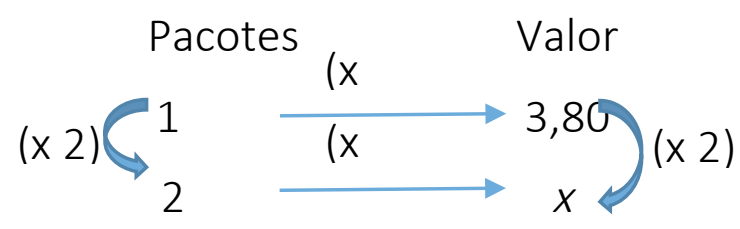

A partir dessa representação, o professor pode, enquanto o aluno resolve, explorar a relação entre as variáveis (Pacotes e Valor), seja nos aspectos dimensionais ou numéricos. Esse mesmo caminho exploratório poderia acontecer nos demais 23 problemas formulados pelos alunos.

No que tange aos problemas de proporção envolvendo a divisão, detectamos que todas as 4 formulações a abarcaram como partilha equitativa (partição). Segundo Vergnaud (2014), esse tipo de estrutura envolve quatro unidades de medidas. Assim, identificá-la nos enunciados não é extremamente difícil, uma vez que expressões do tipo "dividiu por [...]", "dividir em [...]", "quantas [...] cada receberá [...]", são comuns nesses problemas. Segundo Vergnaud (2014), a divisão equitativa apresenta uma correspondência de um-para-um, ou seja, são problemas nas quais o objetivo é determinar o valor unitário, isto é, o valor que "cabe" a cada um dos elementos do divisor. Essa característica pode ser vista na formulação de A18-11, por exemplo. Vejamos a Figura 4. 
Figura 4: Problema do aluno A18-11. Fonte: Arquivo dos autores.

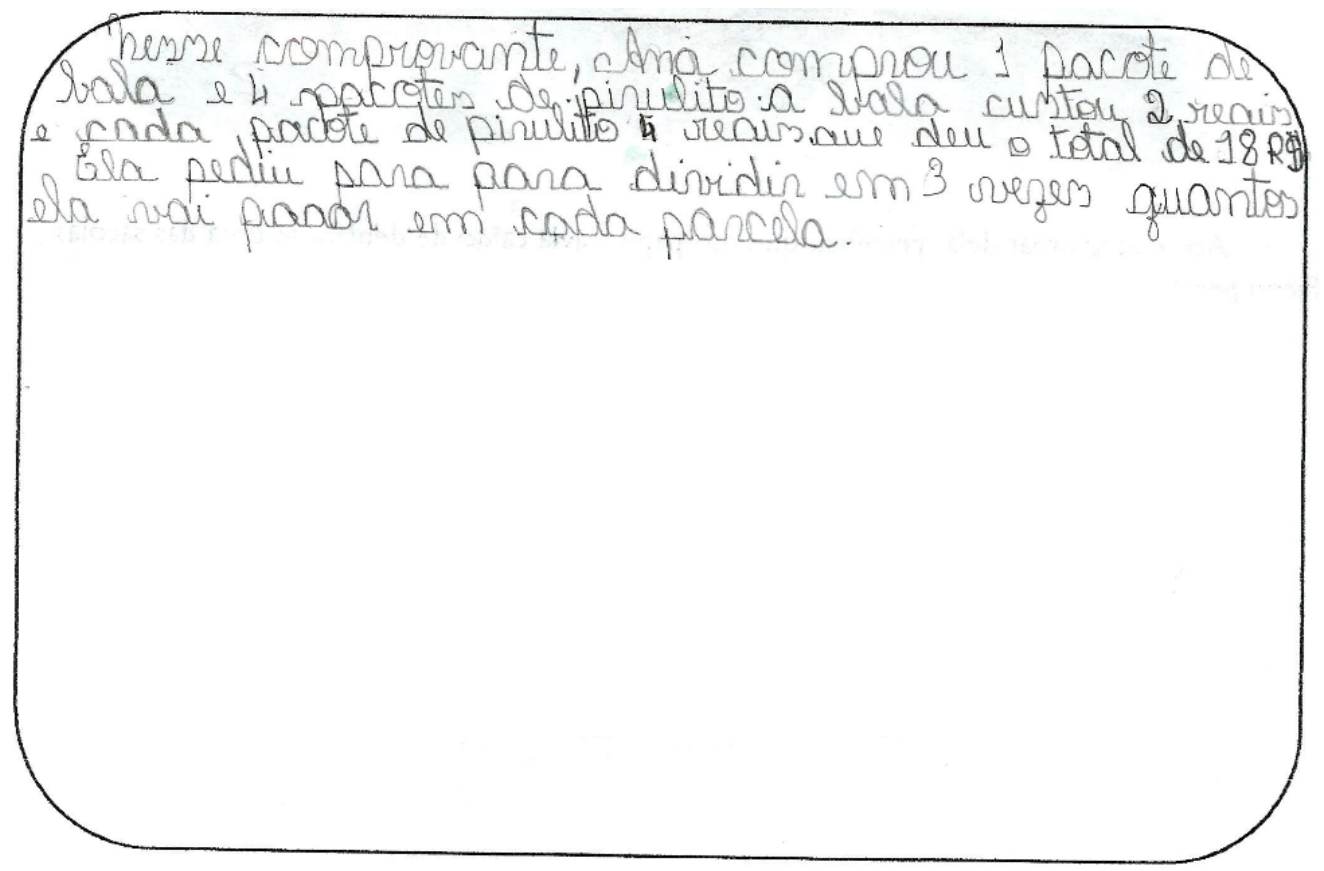

Nessa proposta, o autor deseja que seja calculado o valor de cada parcela ao dividir por 8 o valor total da compra (já apresentado por ele). Existe uma relação proporcional entre "Parcelas" e "Valor", ou seja, se a soma de 3 parcelas resulta em $\mathrm{R} \$ 18,00$, então o valor de uma parcela é decorrente da terça parte do valor total. Esse problema poderia ser resolvido também a partir de um operador-escalar (por meio de uma divisão) ou de um operador-função (por meio de uma multiplicação), conforme podemos ver a seguir.

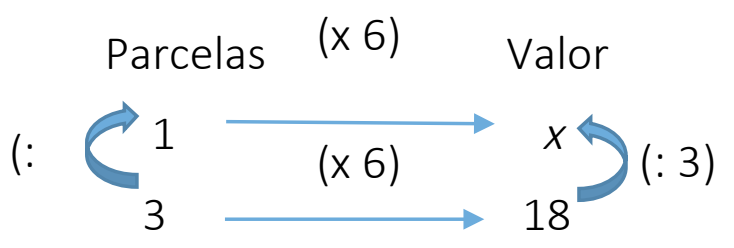

Assim, o professor poderia levar a discussões sobre a possibilidade de se realizar uma divisão a partir de uma multiplicação, tendo em vista a presença do operador-função. Nesse caso, Vergnaud (2014, p. 241) aponta que "[...] é preciso encontrar o valor unitário, conhecendo-se o elo de correspondência entre duas grandezas de natureza diferente". Assim, da mesma forma que se passa de 3 parcela para 1, dividindo-se por 3, também se passa de $\mathrm{R} \$ 18,00$ para "o valor de cada parcela" dividindo-se pelo mesmo operador-escalar. Além disso, o resultado do problema também poderia ser encontrado passando-se de 3 parcelas para $\mathrm{R} \$ 18,00$, multiplicando-se por 6 , e de 1 parcela para $x$ reais também multiplicando por 6 , o que configura o operador-função, definido por Vergnaud (2014). 
Além do problema de A18-11, encontramos também uma outra proposta elaborada por A08-10 na qual evidencia-se unicamente a divisão. Nela, o autor traz diversas quantidades de produtos e solicita que seja calculado quanto de cada um os 5 netos da Dona Celeste receberá. A solução não é muito complexa, contudo requer a realização de 5 divisões, sendo uma para cada produto. Essas informações poderão ser testemunhadas na Figura 5.

Figura 51: Problema do aluno A08-10. Fonte: Arquivo dos autores.

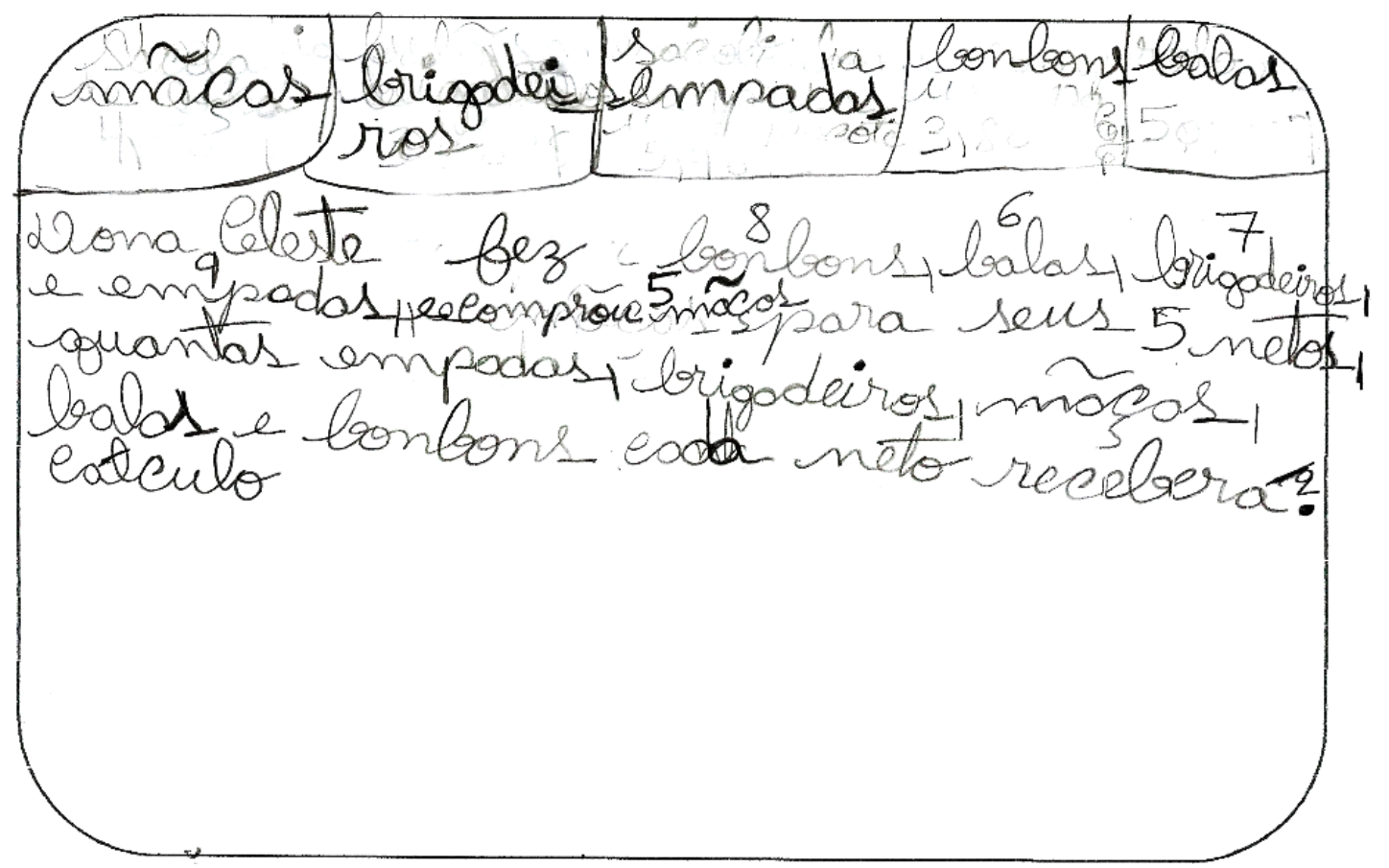

Nesse caso, a resolução poderia ser realizada por meio do operador-escalar (pode-se também pelo operador-função) e esquematizada da seguinte maneira:

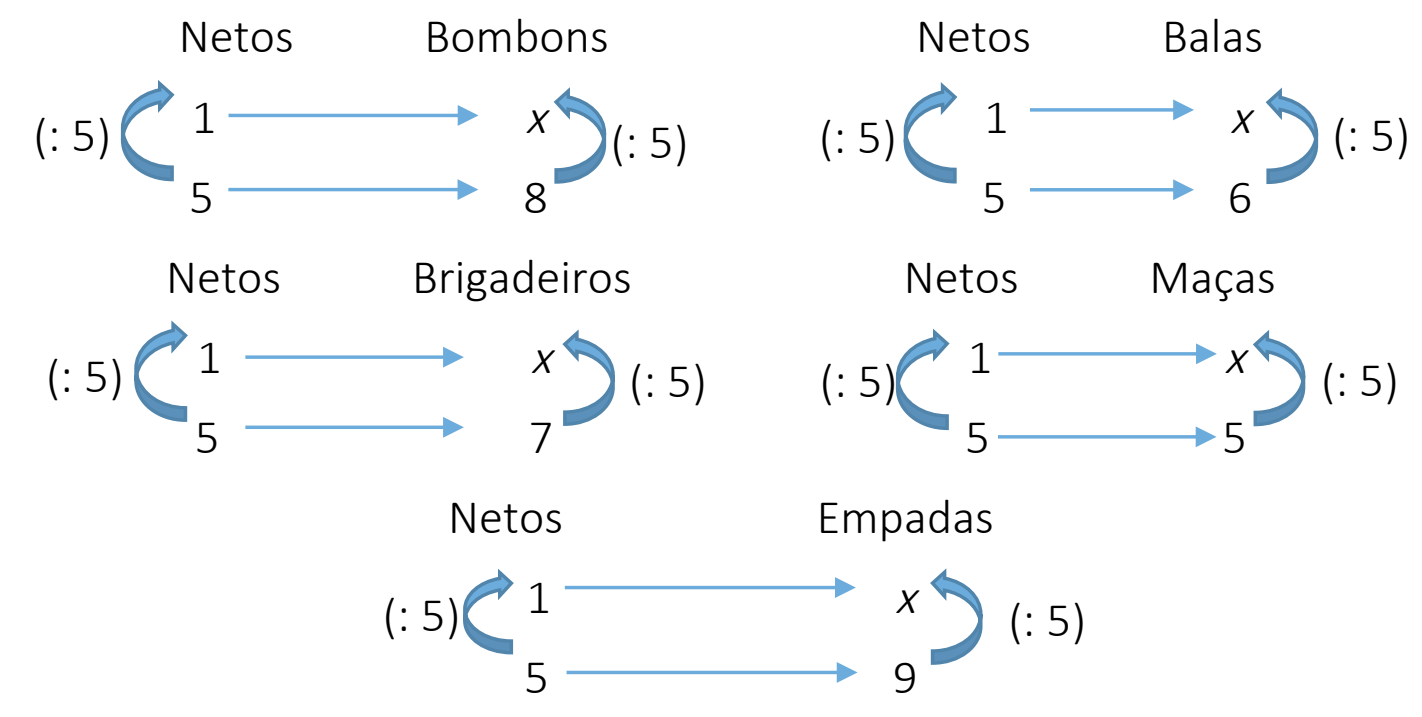


Esse tipo de problema pode acarretar discussões relativas as respostas que serão encontradas. Com exceção das maçãs, as demais divisões apresentam resto diferente de zero quando resolvida no conjunto dos números naturais. Caso o interesse seja em discutir o conjunto dos racionais, essa poderia ser uma boa proposta de atividade para ser levada para a sala de aula. Assim, seria interessante refletir sobre essa perspectiva e também a respeito das unidades (caixa, unidade ou pacote) correspondentes a cada produto. Para amenizar tais dúvidas quanto a solução, Chica (2001, p. 160) orienta "expor à apreciação de um leitor, o qual pode ser um colega da sala [...] para detectar o entendimento do que se quis escrever e, em seguida, aprimorar o texto [...]". O autor não especificou, por exemplo, se as balas são distribuídas entre netos na forma de unidades ou pacotes. É necessária uma maior clareza sobre esse aspecto.

Nossas intenções nesta Dimensão são também de verificar quantos dos 25 problemas formulados possibilitariam discussões acerca do enunciado, da resolução ou da solução. Seguindo esse pensamento, identificamos 4 problemas que poderiam levar a posteriores discussões em sala de aula. O problema de A08-10 (Figura 37) já foi discutido anteriormente, portanto não convém reapresentá-lo. Restam, portanto, três problemas a serem analisados.

O problema de A19-11 é assim transcrito: "Vaniuda comprou 7 pacotes de balas com 50 unidades para o aniversário de Pedrinho. Ela quis dividir as balas entre o aniversário e ela e o filho. Quantas balas ela dividiu entre o aniversário e ela e o filho"? A proposta em si acarreta alguns questionamentos, principalmente em relação a pergunta a ser respondida. Não dá para entender se o autor gostaria que as balas fossem divididas entre os "convidados", a mãe e o filho ou se é somente entre a mãe e o filho. Se pensarmos em uma festa de aniversário, não faria muito sentido dividir as balas compradas entre a mãe (que fez a festa) e aniversariante (dona da festa). Por outro lado, se as balas deveriam ser divididas entre os convidados, a mãe e o aniversariante então devem ser apresentados no enunciado a quantidade de convidados da festa. Para este caso, Chica (2001) sugere que quando a pergunta não está de acordo com a resposta, que seja proposto aos alunos modificarem o texto do enunciado para que abarque a resposta desejada. É um modo, segundo ela, de fazer com que os alunos percebam que é possível transformar o texto para torna-lo adequado a situação que se propõe.

Já a proposta de A03-10, retrata uma compra de produto para realização de uma festa de aniversário, cujos produtos foram 5 balas, 1 bolo e 1 refrigerante. 0 autor não especificou se o valor referente a cada bala é unitário ou já é o total a ser pago pelas 5 balas. Assim, seriam necessárias discussões a respeito do enunciado para que o resolvedor pudesse desenvolver seu raciocínio e a resolução do problema. Similarmente, o problema A04-10 compartilha de uma das análises: o autor não especificou se o valor referente aos sacos de balas é unitário ou total. Assim, 
caberiam discussões relativas a escrita do enunciado para melhor entendimento do problema, seguindo o posicionamento de Chica (2001) no que diz respeito a intervenções na formulação de problemas.

Em suma, entendemos que esses problemas - por nós discutidos e analisados -, e as demais 21 propostas podem ser interessantes para o trabalho em sala de aula. Podem proporcionar reflexões a respeito da formulação de problemas, como por exemplo: i) atentar-se as relações explicitadas no enunciado e ii) cuidado ao exprimir as ideias. Segundo Pinheiro e Vale (2013), os alunos não estão habituados a formular problemas, o que os levam a produzir problemas com enunciados com escassez de dados, desorganizados e, por vezes, de difícil compreensão.

\begin{tabular}{|l|l|}
\hline \multirow{4}{*}{ Outras Especificações } & $\begin{array}{l}\text { Que sejam atribuídos nomes aos personagens, } \\
\text { possibilidade (s) para o (s) produto (s) } \\
\text { comprado (s) e descrição do enredo. }\end{array}$ \\
\cline { 2 - 3 } & Que os alunos expressem, nos problemas \\
& formulados, seus interesses pessoais. \\
\hline
\end{tabular}

Esta parte das análises tem como objetivo conhecer um pouco mais dos problemas formulados. No discorrer do aporte teórico sobre Formulação de Problemas, mencionamos a importância da motivação nas aulas de matemática e destacamos a possibilidade dessa prática ser um caminho na produção de problemas motivadores de aprendizagem. Mas, o que pode motivar os alunos a resolverem os seus problemas?

Em busca de possíveis respostas, analisamos as produções dos participantes no que se referem as características estruturais (personagens, produtos e enredo) e os motivos que os levaram a formular o seu problema do modo que foi apresentado. Segundo Dante (2009), os problemas formulados por eles podem motivá-los a ler e a resolver por que são seus e, para Boavida et al. (2008), o encorajamento em formular seus problemas e resolvê-los é um contexto muito rico para o desenvolvimento da capacidade de resolver problemas. Lembremo-nos de que um dos sentidos de se trabalhar a Formulação de Problemas em sala de aula é possibilidade de despertar a criatividade e permitir que os problemas abarquem interesses pessoais dos próprios alunos, sejam eles quais forem.

Em relação aos personagens presentes nas histórias, a maior parte dos alunos incluiu nomes muito próximos de sua vivência social, como nome do pai, mãe, tio avó/avô e amigos. Os produtos escolhidos para o comprovante de compras foram os mais variados, contudo percebemos uma relação muito forte com festas de aniversário. Assim, foram enunciados produtos, tais como: bolo, bala, bolas, 
brigadeiro, bombons, refrigerantes, torta, marshmallow, toalha de mesa, bala de coco, jujubas, velas e pirulitos. Além desses, tivemos também a presença de outras possibilidades, como: leite, arroz, pão de forma, camisa, blusa, biscoito, óculos, frutas, maças e empadas. A maioria afirmou que esses são os seus produtos preferidos e que gostam de comprar.

O enredo principal, retratado em quase todos os problemas, diz respeito a uma compra. Todas essas afirmações podem ser comprovadas, seja nas justificativas que apresentaremos a seguir ou nos próprios problemas apresentados no decorrer da Dimensão Epistemológica. Os sentidos atribuídos aos problemas foram tantos e os mais diversos. É muito interessante ver as justificavas dos alunos para seus respectivos problemas. Podemos ver, por exemplo, nas falas dos alunos A09-11 (Figura 6), A18-11 (Figura 7) e A08-10 (Figura 8) os motivos que os levaram a formular os seus problemas.

Figura 6: Justificativa do aluno A09-11. Fonte: Arquivo dos autores.

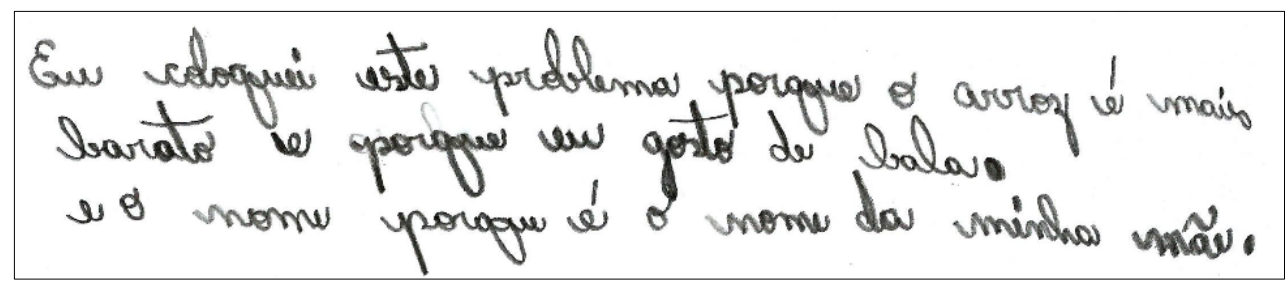

Figura 7: Justificativa do aluno A18-11. Fonte: Arquivo dos autores.

Por que en gosto de bala e de pisulito. O nome en ma sali, mais gosto de foi por que e' meio realista, e en fir de dividir pois

Figura 82: Justificativa do aluno A08-10. Fonte: Arquivo dos autores.

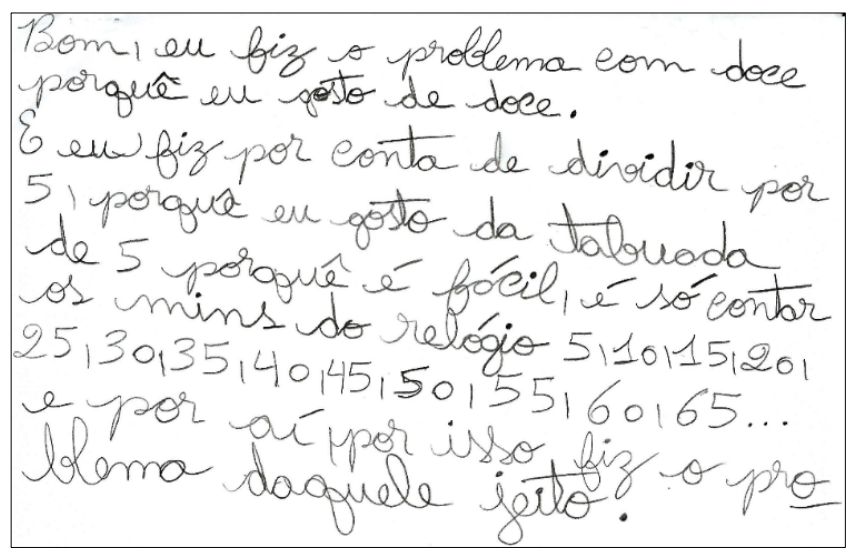


Nas justificativas dos alunos A18-11 e A08-10, encontramos os motivos que os levaram a formular, por exemplo, um problema de divisão. Um fato interessante em A18-11 reside no seu olhar de que o preço escolhido para os seus produtos é "meio realista". Vemos uma preocupação em colocar, como dados no problema, valores quase que reais.

Muitas vezes, nós professores, não nos damos conta de que determinados problemas não são interessantes aos olhos de quem os resolve. Ser legal, divertido e interessante são quesitos importantes quando falamos de motivação em resolução de problemas e por isso que Dante (2008) afirma que os problemas formulados pelos alunos podem despertar o interesse em resolvê-los. É um processo que carregou consigo interesses e ideias únicas de cada indivíduo. Nesse sentido, oportunizar a Formulação de Problemas é também levar a construção do sentimento de pertencimento, que acarreta uma motivação pessoal. Assim, vemos nas justificativas de A02-11 (Figura 9) e A01-10 (Figura 10) alguns de seus sentimentos perante seus problemas.

\section{Figura 9: Justificativa do aluno A02-11. Fonte: Arquivo dos autores.}

$$
\begin{aligned}
& \text { Ochei que ia te dificuldade ma hora de resober. } \\
& \text { of por que eu acher que precis a mais ou menos ibso para } \\
& \text { uma ferta do pifarma. }
\end{aligned}
$$

Figura 103: Justificativa do aluno A01-10. Fonte: Arquivo dos autores.

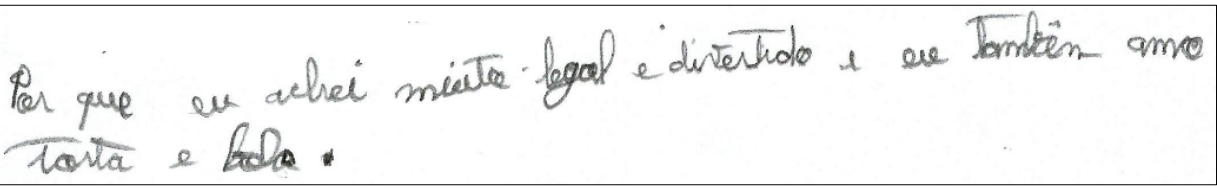

Portanto, acreditamos que por meio dessas justificativas seja possível inferir que a prática de Formulação de Problemas carrega consigo experiências, desejos, interesses, autenticidade e motivação pessoal de cada indivíduo e isso é um dos fatores que podem levá-los a se interessarem pela resolução do seu problema.

\section{Considerações Finais}

Após a análise dos dados, concluímos que esta proposta de atividade, com base na história "A compra misteriosa", pode contribuir no ensino de multiplicação e divisão à medida que propicia a prática de Formulação de Problemas em sala de aula. É um caminho para se pensar e apresentar essa prática nas aulas de matemática, 
levando a produção de problemas a serem discutidos e analisados para fins de aprendizagem.

Em relação aos problemas formulados pelos alunos, destacamos que os mesmos possuem potencial educativo e podem ser utilizados pelo professor (a) no processo de ensino dessas operações, uma vez que trazem consigo o envolvimento da multiplicação e da divisão como partilha equitativa (partição) em problemas de proporção simples. Para além, carregam consigo elementos motivacionais necessários ao envolvimento dos alunos nas aulas de matemática.

Além dessas conclusões, inferimos também a existência de algumas propostas que podem contribuir em debates acerca de suas resoluções, soluções e enunciados uma vez que apresentam algumas lacunas provenientes da ausência da prática de Formulação de Problemas. Isso decorre do fato de que os alunos são pouco incentivados a formularem problemas nas aulas de matemática, tendo por sua vez seu papel de resolvedores de problemas apresentados pelo professor. Quanto menos se tem contato com a Formulação, mais dificuldades os estudantes poderão apresentar durante a elaborados de suas propostas.

Outra conclusão pertinente é a evidência de uma grande parte das formulações tratarem de uma festa de aniversário ou os produtos se remeterem a ela. Talvez o nome da cidade (Cidade das Festas) e o nome da loja (Cantinho das Festas) no respectivo comprovante possam ter influenciado à construção de problemas envolvendo esse contexto. Assim, acreditamos que retirar da história o nome "Cidade das Festas" e "Cantinho das Festas" seja uma decisão oportuna, a qual poderá ampliar e dar abertura a novas relações ou novos contextos. Por consequência, necessitamos omitir também o endereço no mesmo comprovante.

Além dessa, a partir a pesquisa efetuamos outras mudanças na atividade proposta, a fim de refiná-la e torná-la mais propícia para o ensino e a aprendizagem dos conceitos envolvidos. Mudamos os balões que representam as falas dos personagens, uma vez que há diferença entre "fala" e "pensamento". Na versão apresentada na análise à priori, foram inseridas falas dentro de balões que, em teoria, têm por objetivo representar pensamentos. Outra mudança diz respeito ao comando da atividade, que assim foi rescrita: "Com base nessa história, o que você acha que mãe dele comprou? Formule um problema de multiplicação ou divisão e depois peça para o seu colega resolvê-lo. Vamos lá!? Use a sua imaginação!". Assim, esperamos que a proposta possa ser utilizada em outros contextos e motivar novas ações semelhantes, contribuindo assim para uma maior inserção de formulações de problemas em todas as etapas da Educação Básica. 
BOAVIDA, A. M. R. et al. A Experiência Matemática no Ensino Básico. Programa de Formação Contínua em Matemática para Professores dos 1.ㅇ e 2.을 Ciclos do Ensino Básico. Lisboa, 2008.

BROWN, S. I.; WALTER, M. I. Problem Posing: Reflections and Applications, Lawrence Erlbaum Associates, Hillsdale, New Jersey. 1993.

CHICA, C. H. Por que formular problemas? In: SMOLE, K. S.; DINIZ, M. I. (Org.). Ler, escrever e resolver problemas: habilidades básicas para aprender matemática. 1. ed. reimp. São Paulo: Artmed, 2001. p. 87-97

D'AMORE, B. II problema di matematica nella pratica didattica. 1. ed. Modena: Digital Docet, 2014.

DANTE, L. R. Formulação e resolução de problemas de matemática: teoria e prática. 1. ed. São Paulo: Ática, 2009.

DINIZ, M. I. Resolução de Problemas e Comunicação. In: SMOLE, K. S.; DINIZ, M. I. (Org.) Ler, escrever e resolver problemas: habilidades básicas para aprender matemática. 1. ed. reimp. São Paulo: Artmed, 2001. p. 87-97.

ENGLISH, L. Children's problem posing within formal and informal context. Journal for Research in Mathematics Education, 29 (1), 1998, p. 83-107.

ENGLISH, L. D. The development of fifth-grade children's problem-posing abilities. Educational Studies in Mathematics, 34, 1997, p. 183-217.

FREIRE. P. Pedagogia da Autonomia: saberes necessários à prática educativa. 51. ed. Rio de Janeiro: Paz e Terra, 2015.

KILPATRICK, J. Problem formulating: where do good problems come from? In A. H. Schoenfeld (Ed.): Cognitive science and mathematics education (pp. 123147). Hillsdale, NJ: Erlbaum. 1987.

MOREIRA, M. A. Teorias de aprendizagem. 2. ed. ampl. - [Reimpr]. São Paulo: E.P.U, 2015

NCTM. An Agenda for Action: Recommendations for School Mathematics in the 1980's. Reston, VA: National Council of Teachers of Mathematics, 1980.

NCTM. Professional Standards: for School Mathematics. Reston, VA: National Council of Teachers of Mathematics, 1991.

PINHEIRO, S.; VALE, I. A criatividade na resolução e formulação de problemas: uma experiência didática numa turma do 5ㅇ ano de escolaridade. 09/09/2013. 199 f. Dissertação de Mestrado em Educação) Instituto Politécnico de Viana do Castelo, Viana do Castelo - PT, 2013. 
POZO, J. I. (Org). A solução de problemas. Porto Alegre: ArtMed, 1998.

SILVER, E. A; CAI, J. An analysis of arithmetic problem posing by middle school students. Journal for Research in Mathematics Education, 27 (5), 1996, p. 521-539.

SILVER, E. A; CAI, J. Assessing students' mathematical problem posing. Teaching Children Mathematics, 12 (3), 2005, p. 129-135.

SILVER, E. A; CAI, J. Mathematical problem posing and problem solving by middle school student. Paper presented at the annual meeting of the American Educational Research Association. Atlanta, GA. 1993.

SILVER, E. A; MAMONA, J. Problem posing by middle school teachers. In: C. A. Maher, G. A. Goldin \& R. B. Davis (Eds). Proceedings of the Eleventh Annual Meeting of the North American Chapter of the International Group for the Psychology of Mathematics Education. New Brunswick, NJ: Rutgers University. 1989. p. 263-269.

SILVER, E. A. et al. Posing mathematical problems: an exploratory study. Journal for Research in Mathematics Education. 27 (3), 1996, p. 293-309

SILVER, E. A. On mathematical problem posing. For the Learning of Mathematical. 14 (1), 1994, p. 19-28.

SILVER, E. Fostering creativity through instruction rich in mathematical problem solving and problem posing. ZDM, (3). 1997, p. 75-80.

VEGNAUD, G. Algunas ideas fundamentales de Piaget en torno ala didáctica. Perspectivas, v. 26, n. 10. 1996, p. 195-207

VEGNAUD, G. Multiplicative structures. In: HIEBERT, H.; BEHR, M. (Eds.). Research Agenda in Mathematics Education. Number Concepts and Operations in the Middle Grades. Hillsdale, N.J.: Lawrence Erlbaum, 1988. pp. 141-161.

VERGNAUD, G. A criança, a matemática e a realidade: problemas do ensino de matemática na escola elementar. Tradução: Maria Lucia Faria Moro. ed. rev. Curitiba: Ed. da UFPR, 2014. 322p.

VILA, A.; CALLEJO, M. L. Matemática para aprender a pensar: o papel das crenças na resolução de problemas. Porto Alegre: Artmed, 2006. 